$$
\text { ANL/mso/CP. } 102116
$$

\title{
Borocarbide Thin Films And Tunneling Measurements
}

M. Iavarone ${ }^{1,2}$, A. Andreone ${ }^{1}$, A. Cassinese ${ }^{1}$, R. Dicapua1, L. Gianni1, R. Vaglio1, Y.DE Wilde ${ }^{2}$, and G.W. Crabtree

${ }^{1}$ INFM-Dipartimento di Scienze Fisiche, Universita di Napoli Federicoll, Piazzale Tecchio 80, I80125 Napoli, Italy

${ }^{2}$ Materials Science Division-Science Technology Center for Superconductivity, Argonne National Laboratory, Argonne, Illinois 60439

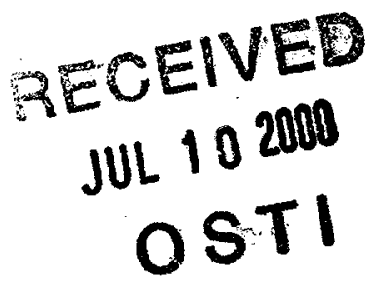

NATO workshop entitled "Rare Earth Transition Metal Borocarbides (Nitrides) : Superconducting, Magnetic and Normal State Properties from June 13 to June 19 in Dresden, Germany

\footnotetext{
The submitted manuscript has been created by the University of Chicago as Operator of Argonne National Laboratory ("Argonne") under Contract No. W-31-109-ENG-38 with the U.S. Department of Energy. The U.S. Government retains for itself, and others acting on its behalf, a paid-up, nonexclusive, irrevocable worldwide license in said article to reproduce, prepare derivative works, distribute copies to the public, and perform publicly and display publicly, by or on behalf of the Government.
}

This work was supported by the U.S. Department of Energy, Office of Science, under contract \#W-31-109-ENG-38 


\section{DISCLAIMER}

This report was prepared as an account of work sponsored by an agency of the United States Government. Neither the United States Government nor any agency thereof, nor any of their employees, make any warranty, express or implied, or assumes any legal liability or responsibility for the accuracy, completeness, or usefulness of any information, apparatus, product, or process disclosed, or represents that its use would not infringe privately owned rights. Reference herein to any specific commercial product, process, or service by trade name, trademark, manufacturer, or otherwise does not necessarily constitute or imply its endorsement, recommendation, or favoring by the United States Government or any agency thereof. The views and opinions of authors expressed herein do not necessarily state or reflect those of the United States Government or any agency thereof. 


\section{DISCLAIMER}

Portions of this document may be illegible in electronic image products. Images are produced from the best available original document. 


\title{
BOROCARBIDE THIN FILMS AND TUNNELING MEASUREMENTS
}

\author{
M. IAVARONE ${ }^{(* t)}$, A.ANDREONE ${ }^{(*)}$, A.CASSINESE ${ }^{(*)}$, R.DICAPUA $^{(*)}$, \\ L.GIANNI (*), R.VAGLIO ${ }^{(*)}$, Y.DE WILDE ${ }^{(t), 1}$ and G.W. CRABTREE ${ }^{(t)}$

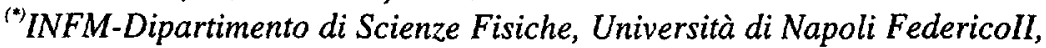 \\ Piazzale Tecchio 80, I-80125 Napoli, Italy \\ (") Materials Science Division-Science and Technology Center for \\ Superconductivity, Argonne National Laboratory, Argonne, IL 60439
}

\section{Introduction}

Thin films represent the basic element for most electronic devices, but can be also a very convenient sample form to realize fundamental physics experiments. In particular in the field of superconductivity thin films have been profitably used for microwave surface impedance measurements, that represent key experiments to discriminate between the possible superconducting gap symmetries, and for the realization of planar juncions, necessary for accurate tunneling or Andreev reflection experiments.

With this in mind our group has grown and extensively characterized both nonmagnetic and magnetic superconducting borocarbide [1,2] thin films. Using magnetron sputtering technique, it was possible to produce for the first time in-situ, high quality, caxis oriented thin films [3].

In the present paper we will briefly review our previous activity mainly related to non magnetic borocarbides $(\mathrm{RE}=\mathrm{Y}, \mathrm{Lu})$ and present recent results concerning microwave surface impedance measurements and $\mathrm{S} / \mathrm{N}$ planar junctions based on $\mathrm{LuNi}_{2} \mathrm{~B}_{2} \mathrm{C}$ thin films. The body of our data unambiguously confirm the BCS nature of superconductivity in borocarbides.

\section{Film preparation and characterization}

$\mathrm{Re}-\mathrm{Ni}_{2} \mathrm{~B}_{2} \mathrm{C}(\mathrm{Re}=\mathrm{Y}, \mathrm{Er}, \mathrm{Lu})$ films were prepared by planar magnetron sputtering technique as described in ref. 3. Two-inch diameter Re-Ni2 $\mathrm{B}_{2} \mathrm{C}$ targets were prepared by arc melting stoichiometric amounts of the raw materials under a dry argon atmosphere. $\mathrm{MgO}, \mathrm{Al}_{2} \mathrm{O}_{3}, \mathrm{LaAlO}_{3}$ and diamond substrates were placed "on axis" at $9 \mathrm{~cm}$ from the target surface and heated up to about $800^{\circ} \mathrm{C}$ using a molybdenum heater. The base system pressure $P_{\text {in }}$ just before sputtering was in the low $10^{-6} \mathrm{~Pa}$ range. A key role

\footnotetext{
1 Present address: CNRS-UPR5 Spectroscopie en Lumiere Polarisee Ecole Superieure de Physique et de Chimie Industrielles Bat.C 10 Rue Vauquelin, 75231 PARIS CEDEX05, FRANCE
} 
in obtaining high quality films was played by the substrate temperature $T_{S}$ and by the target quality.

Although superconducting films were obtained on all the substrates used, high quality films with $\mathrm{Tc} \cong \mathrm{Tc}($ bulk) and high residual resistivity ratio $(R R R=\rho(300 K) / \rho(20 K) \geq 6)$ were reproducibly obtained only for $\mathrm{YNi}_{2} \mathrm{~B}_{2} \mathrm{C}$ on $\mathrm{MgO}$ substrates. Due to the inferior target purity for $\mathrm{Re}=\mathrm{Er}$ and Lu these films showed lower RRR ( $\leq 3$ ) and similar results were obtained using different substrates. The film resistivity, determined by a four probe arrangement, was close to bulk values for $\mathrm{YNi}_{2} \mathrm{~B}_{2} \mathrm{C}(50 \mu \Omega \mathrm{cm}$ at $300 \mathrm{~K})$ and larger for both $\mathrm{ErNi}_{2} \mathrm{~B}_{2} \mathrm{C}$ and $\mathrm{LuNi}_{2} \mathrm{~B}_{2} \mathrm{C}$ (170 and $100 \mu \Omega \mathrm{cm}$ at $300 \mathrm{~K}$ respectively). The temperature dependence of the resisitivity of our films is extensively discussed in [4] and exhibits a conventional linear dependence at room temperatures with a tendency towards a high temperature "saturation" for lower quality samples. The low temperature data could be described by a $T^{2}$ power law as in single crystals [5].

For all films the X-ray $\Theta-2 \Theta$ diffraction pattern revealed the predominant presence of $(00 \mathrm{n})$ reflections.

\section{STM measurements}

STM measurements on $\mathrm{YNi}_{2} \mathrm{~B}_{2} \mathrm{C}$ films were performed at Argonne National Laboratory with a home built low temperature STM using a Pt/Ir tip. The system allows measurements of conductance vs. voltage ( $\mathrm{d} / \mathrm{dV}$ vs. V) characteristics at selected points, recording simultaneously the surface topography. With this apparatus a square Abrikosov vortex lattice in $\mathrm{LuNi}_{2} \mathrm{~B}_{2} \mathrm{C}$ single crystals was observed for the first time [6].

No surface treatment was applied to the samples prior to mounting on the STM. The $\mathrm{dV} / \mathrm{dV}$ vs. $\mathrm{V}$ characteristic presented in Figure 1 is the result of the averaging of 20 individual characteristics recorded at the same spot, after normalization by a slightly parabolic background. The data could be well fitted with a smeared version of the BCSdensity of states:

$$
N(E)=\operatorname{Re}\left\{\frac{|E-i \Gamma|}{\sqrt{(E-i \Gamma)^{2}-\Delta^{2}}}\right\}
$$

which includes the broadening parameter $\Gamma$ [7]. The resulting fitting parameters are $\Delta=2.1 \mathrm{meV}$ and $\Gamma=0.4 \mathrm{meV}$. Combined with a value of $\mathrm{Tc}=15.1 \mathrm{~K}$ the corresponding BCS ratio $2 \Delta / \mathrm{k}_{\mathrm{B}} \mathrm{Tc}$ is equal to $3.2 \pm 0.2$. These values are compatible with previous reports in the literature [8], which confirms the substantial weak-coupling nature of $\mathrm{YNi}_{2} \mathrm{~B}_{2} \mathrm{C}$. More details of the measurements and fitting procedure are reported in ref. 4. 


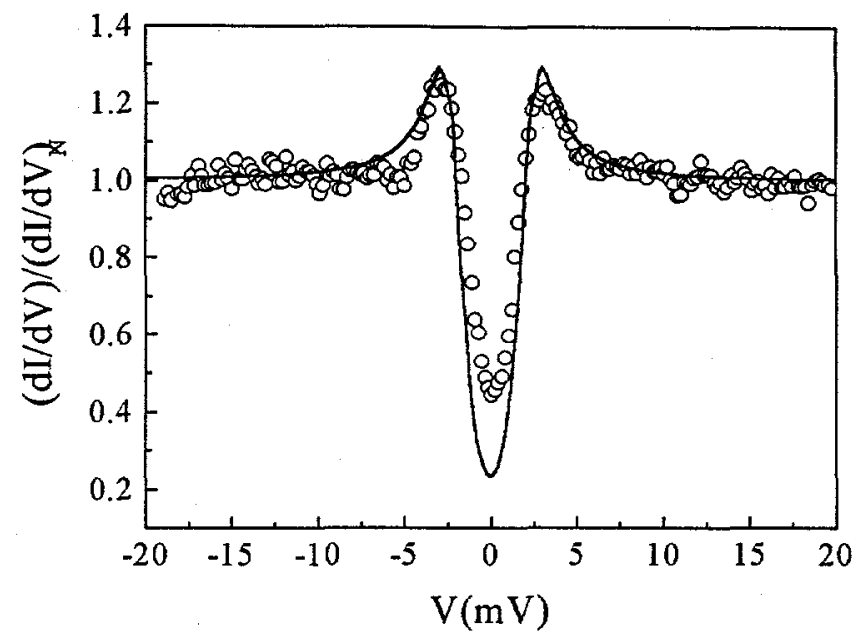

Figure 1. Normalized experimental(dots) and calculated (line) conductance vs. voltage characteristic for a $\mathrm{YNi}_{2} \mathrm{~B}_{2} \mathrm{C}$ film at $\mathrm{T}=4.2 \mathrm{~K}$.

\section{Planar junctions}

Planar tunnel junctions were produced in situ by a special set-up for the interchanging of tantalum shadow masks. In situ cross-type junction geometry (crosssection about $100 \mu \mathrm{m} \times 100 \mu \mathrm{m}$ ) could be produced using different oxide barriers. Some junctions were also made on high quality $\mathrm{LuNi}_{2} \mathrm{~B}_{2} \mathrm{C}$ films deposited on $\mathrm{MgO}$ by pulsed laser ablation [9]. In this case the bottom layer and the barrier $\left(\mathrm{Al}_{2} \mathrm{O}_{3}, \mathrm{MgO}\right.$ or $\left.\mathrm{CeO}_{2}\right)$ were in-situ deposited, while the upper layer was a narrow stripe of lead evaporated in a following stage.

Planar junctions produced to date do not show reproducible tunneling behavior. Occasionally however, with most barriers, junctions exhibiting a clean and stable $\mathbf{S} / \mathrm{N}$ interface behavior were obtained probably through pin-holes like defects in the barrier [10]. A typical I-V curve is reported in the inset of Fig.2. The I-V curves and their numerical derivatives were well described by the standard BTK theory [11]. From the conductance minima the value of the superconducting gap $\Delta=2.0 \mathrm{mV}$ at $\mathrm{T}=4.2 \mathrm{~K}$ for $\mathrm{LuNi}_{2} \mathrm{~B}_{2} \mathrm{C}$ was obtained, that leads to $2 \Delta_{0} / \mathrm{kTc}=3.0 \pm 0.2$ in agreement with the STM results on single crystals [6].

Figure 2 shows the temperature dependence of $\Delta$ for two different junctions which agrees very well with the BCS prediction in the full temperature range. This is in contrast with a recent theoretical prediction based on the presence of significant pairbreaking effects in $\mathrm{LuNi}_{2} \mathrm{~B}_{2} \mathrm{C}$ [12]. 


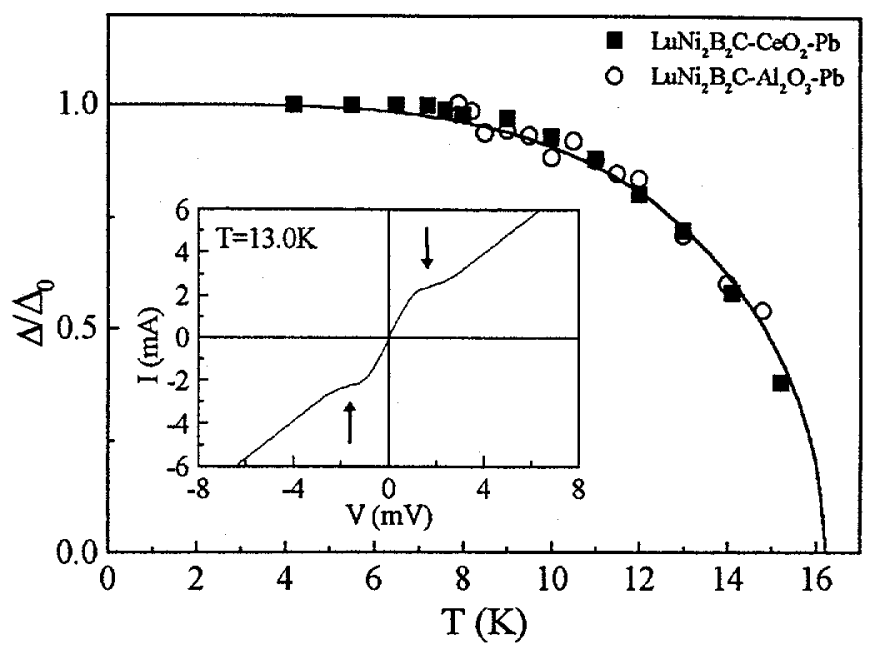

Figure 2. $\mathrm{LuNi}_{2} \mathrm{~B}_{2} \mathrm{C}$ measured gap for two different junctions as a function of the temperature together with the theoretical BCS curve (solid line). Inset: typical $\mathrm{I}-\mathrm{V}$ curve recorded at $\mathrm{T}=13.0 \mathrm{~K}$. The arrows show the gap value.

\section{Surface impedance measurements}

LuNi $\mathrm{B}_{2} \mathrm{C}$ films grown on $\mathrm{Al}_{2} \mathrm{O}_{3}$, due to the optimal dielectric properties of this substrate, were used to perform microwave surface impedance measurements using a standard network analyzer. A dielectric resonator with a fundamental resonant frequency $\mathrm{f}=19 \mathrm{GHz}$, was realized in a $\mathrm{Cu}$ box making use of two superconducting $10 \times 10 \mathrm{~mm}^{2}$ samples to shield the end faces of a sapphire cylinder (height $\mathrm{h}=3.5 \mathrm{~mm}$, diameter $\mathrm{D}=7 \mathrm{~mm}$ ). For low loss dielectrics the resonator quality factor is limited by conductor losses within the shield.

The quality factor $\mathrm{Q}$ for the resonant system can be expressed as follows:

$$
1 / Q=R_{s} / A_{\text {sup }}+R_{m} / A_{m}
$$

where $A_{\text {sup }}=250 \Omega$ and $A_{m}=2900 \Omega$ are geometrical factors for the conducting surfaces of the resonant system, consisting of the superconducting material and the lateral copper shield, and $R_{s}$ and $R_{m}$ are the surface resistance values for the superconductors and the metal.

Frequency shifts $\Delta f$ are associated with the penetration depth changes $\Delta \lambda$ through the relation:

$$
2 \Delta f / f=\mu_{0} \omega\left(\Delta \lambda_{\text {sup }} / A_{\text {sup }}+\Delta \lambda_{m} / A_{m}\right)
$$

( $\lambda$ being proportional to the surface reactance $X_{s}$ ) 


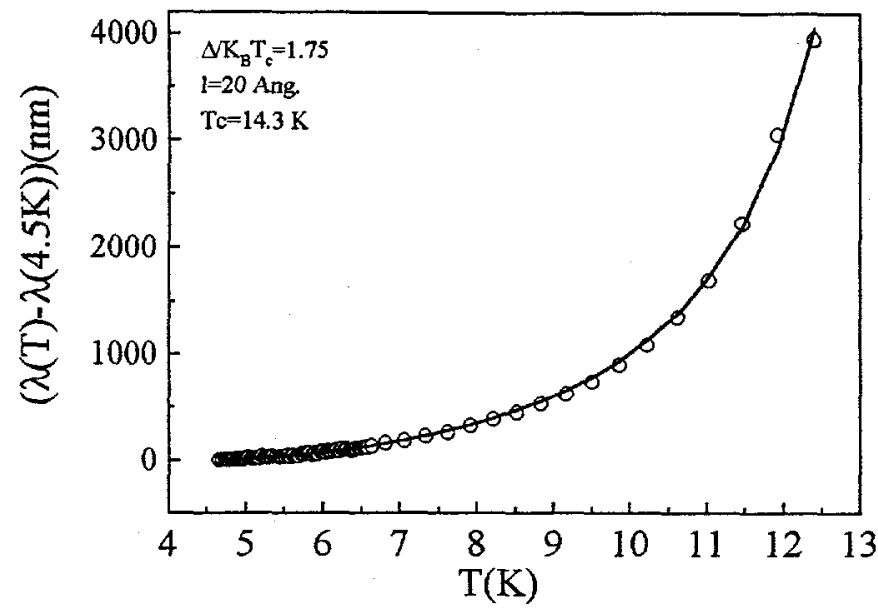

Figure 3 . Temperature dependence of the penetration depth for a $\mathrm{LuNi}_{2} \mathrm{~B}_{2} \mathrm{C}$ films grown on sapphire. The continuous curve represent the BCS fit, in the figure are also reported the fit parameters corresponding to the theoretical curve.

Typical temperature dependence of the penetration depth, obtained by simultaneously measuring $\Delta \mathrm{f}$ as a function of the temperature is reported in Figure 3. The exponential dependence on temperature, characteristic of an activated behavior over a constant energy gap, is clearly exhibited for both curves. The theoretical fitting with standard $B C S$ equations [13] gives a value of $2 \Delta / \mathrm{K}_{\mathrm{B}} \mathrm{T}_{\mathrm{c}}=3.5 \pm 0.4$ consistent with tunneling estimates. Two parameters needed for the BCS fit, the mean free path value at low temperature $1(20 \AA)$ and the critical temperature Tc $(14.3 \mathrm{~K})$, were evaluated from resistivity measurements and inductive measurements respectively.

\section{Conclusions}

The results obtained by our group in thin film fabrication and STM tunneling on superconducting borocarbides $\mathrm{YNi}_{2} \mathrm{~B}_{2} \mathrm{C}$ have been be briefly reviewed. Results concerning the microwave surface impedance and the $\mathrm{S} / \mathrm{N}$ planar junctions on $\mathrm{LuNi}_{2} \mathrm{~B}_{2} \mathrm{C}$ thin films have been also presented and analyzed. These new data unambiguously confirm the full BCS nature of the superconducting gap in borocarbides and the absence of significant pair-breaking effects in $\mathrm{LuNi}_{2} \mathrm{~B}_{2} \mathrm{C}$.

\section{Aknowledgments}

The authors wish to thank G. Grassano, C.Ferdeghini and S.Siri for providing $\mathrm{LuNi}_{2} \mathrm{~B}_{2} \mathrm{C}$ thin films grown by Pulsed Laser Ablation, for stimulating discussions and suggestions; P.Manini and E.Cogliati for the target preparation. The technical support of A.Maggio, S.Marrazzo and S.Avallone is also acknowledged. This work was supported by the US Department of Energy, Basic Energy Sciences-Materials Sciences under contract W-31109-ENG-38. 


\section{References}

1. Cava, R.J., Takagi, H., Zandbergen, H.W., Krajewski, J.J., Peck, Jr W.F., Siegrist, T., Batlogg, B., van Dover, B., Felder, R.J., Mizuhaski, K., Lee, J.O., Eisaki, H., and Uchida, S. (1994) Superconductivity in the quaternary intermetallic compounds $\mathrm{LnNi}_{2} \mathrm{~B}_{2} \mathrm{C}$, Nature 367,252

2. Nagarajan, R., Mazumdar, C., Hossian, Z., Dhar, S.K., Gopalakrishnan, K.V., Gupta, L.C., Godart, C., Padalia, B.D. and Vijayraghavan, R. (1994) Bulk superconductivity at an elevated temperature (Tc $12 \mathrm{~K}$ ) in a nickel containing alloy system Y-Ni-B-C, Phys.Rev.Lett. 72, 274

3. Andreone, A., Iavarone, M., Vaglio, R., Manini, P. and Cogliati, E., (1996) In situ growth and superconducting properties of $\mathrm{YNi}_{2} \mathrm{~B}_{2} \mathrm{C}$ thin films, Appl. Phys. Lett. 69, 118

4. Vaglio, R., Andreone, A., Aruta, C., Cassinese, A., Fontana, F., Crabtree, G.W., Iavarone, M., De Wilde, Y., Maritato, L., Attanasio, C., Coccorese, C., Salluzzo, M., Salvato, M., (1997) Properties of $\mathrm{YNi}_{2} \mathrm{~B}_{2} \mathrm{C}$ Superconducting Thin Films, Phys. Rev. B 56, 934

5. Rathnayaka, K.D.D., Bhatnagar, A.K., Parasiris, A., Naugle, D. G., Canfield, P.C., Cho, B. K. (1997) Transport and superconducting properties of $\mathrm{RNi} 2 \mathrm{~B} 2 \mathrm{C}(\mathrm{R}=$ Y,Lu) single crystals, Phys. Rev. B 55, 8506

6. De Wilde, Y., Iavarone, M., Metlushko, V., Welp, U., Koshelev, A., Aranson, I., Crabtree, G.W. and Canfield, P.C., (1997) Scanning Tunneling Microscopy observation of a square Abrikosov lattice in LuNi $\mathrm{B}_{2} \mathrm{C}$, Phys. Rev. Lett. 78, 4273

7. Dynes, R. C., Narayanamurti, V., and Garno, J. P. (1978) Direct Measurements of Quasiparticle-Lifetime Broadening in a Strong-Coupled Superconductor, Phys. Rev. Lett. 41, 1509

8. Ekino, T., Fujii, H., Kosugi, M., Zenitani, Y., Akimitsu, J. (1996) Tunneling spectroscopy of the superconducting energy gap in $\mathrm{RNi}_{2} \mathrm{~B}_{2} \mathrm{C}(\mathrm{R}=\mathrm{Y}$ and $\mathrm{Lu}) J$. Phys. Rev. B 53, 5640

9. Grassano, G., Cimberle, M.R., Ferdeghini, C., Iavarone, M., Di Capua, R., Vaglio, R., Canepa, F. (in press) Superconducting properties of $\mathrm{LuNi}_{2} \mathrm{~B}_{2} \mathrm{C}$ films and junctions, Physica $C$

10. Platt, C.L., Katz, A.S., Dynes, R.C., Berkowitz, A.E. (1999) Magnetism and Superconductivity-Superconducting Tunneling as a probe of sputtered oxide barriers, Appl. Phys. Lett 75, 127

11. Blonder, G.E., Tinkham, M., Klapwijk, T.M. (1982) Transition from metallic to tunneling regimes in superconducting microconstrictions: Excess current, charge imbalance and supercurrent conversion, Phys. Rev. B 25, 4515

12. Ovchinnikov, Y.N. and Kresin, V.Z., (2000) Magnetic scattering and unusual behavior of the critical fields and other parameters: Application to borocarbides, European Physical Journal B 14, 203

13. Halbritter, J. (1974) On the surface impedance of superconductors Z. Phys. 266, 209 